\title{
DESIGN AND DEVELOPMENT METHODOLOGY OF ADAPTIVE VIBRATION ABSORBER
}

\author{
Rushi Vyas, Rajan Zinzala and Hiren Prajapati \\ Institute of Technology, Nirma University, Ahmedabad, Gujarat, India
}

\begin{abstract}
The aim of this project is to how to reduce vibration through dual cantilever mass mechanism which is call adaptive vibration absorber that is different than the tune vibration absorber. Design incorporates the use of two concentrated masses cantilevered from two rods. The adaptive solution is achieved by moving the two masses along the length of the rod, producing a changing natural frequency for the absorber device. To do so we applied this system to frequency range of 30 to $80 \mathrm{~Hz}$.For our design we take concentrated masses of $1.2 \mathrm{~kg}$. When we change length from $81.5 \mathrm{~mm}$ to 210 $\mathrm{mm}$. So, our frequency range will be in range of 80 to $30 \mathrm{~Hz}$ (natural frequency).We would design the absorber for the setup having maximum acceleration at $50 \mathrm{~Hz}$ frequency and observe the amount of vibrations absorbed by it.
\end{abstract}

Key words: Vibration Absorber and FFT Analysis

Cite this Article: Design and Development Methodology of Adaptive Vibration Absorber, Rushi Vyas, Rajan Zinzala and Hiren Prajapati International Journal of Design and Manufacturing Technology 7(3), 2016, pp. 1-11.

https://iaeme.com/Home/issue/IJDMT?Volume=7\&Issue=3

\section{INTRODUCTION}

In an engineering application there may be one or multiple motion / power transferring elements. There may be linear, sliding or rotary elements. For any such element, while transferring power/motion there are certain amount of vibrations which are caused.

The cause of vibrations may be: - Unbalance, configuration of the system itself, inaccurate machining, improper tolerances of dimensions etc.

These vibrations may cause many problems in operation and it may lead to failures too. So it is very necessary to eliminate these vibrations in order to achieve a perfect stable system for power transmission. 


\subsection{Vibration elimination}

Vibrations can be eliminated completely or partially by attaching an additional system to our element. We can use various dampers, isolators or Absorbers. Damper is a system having very high damping, so the amplitude of vibration decreases by a large amount by adding such stiffness or damping element to our existing system.

Isolators are the system which tries to isolate the element or the existing system in order to decrease or completely eliminate the vibrations in our element.

While absorbers are the systems that decrease the amount of vibrations simply by using the concept of negative superposition. Superposition is the process of adding the existing vibrations with the vibrations caused by an external system.

\subsection{Vibration absorbers}

As explained earlier the absorber is a system which tries to eliminate vibrations by negative superposition. Basically what happens is:

Suppose the nature of my vibrations occurring on an element is

$\mathrm{X}(\mathrm{t})=\mathrm{A} \sin (\mathrm{w} t+\mathrm{Q})$

So, we can add a particular system which has same nature of vibration function by opposite nature:

$X^{\prime}(t)=-A \sin (w t+Q)$

So:

$\mathrm{x}(\mathrm{t})+\mathrm{x}^{\prime}(\mathrm{t})=0$

From these example we can say that a perfect vibration absorber absorbs the vibration totally and makes the system vibration free. The variables to look for the vibrations are: Modes, Frequency and damping.

The diagram below shows the nature and tendency of an ideal or perfect absorber:

$X(t)$ [system vibrations]
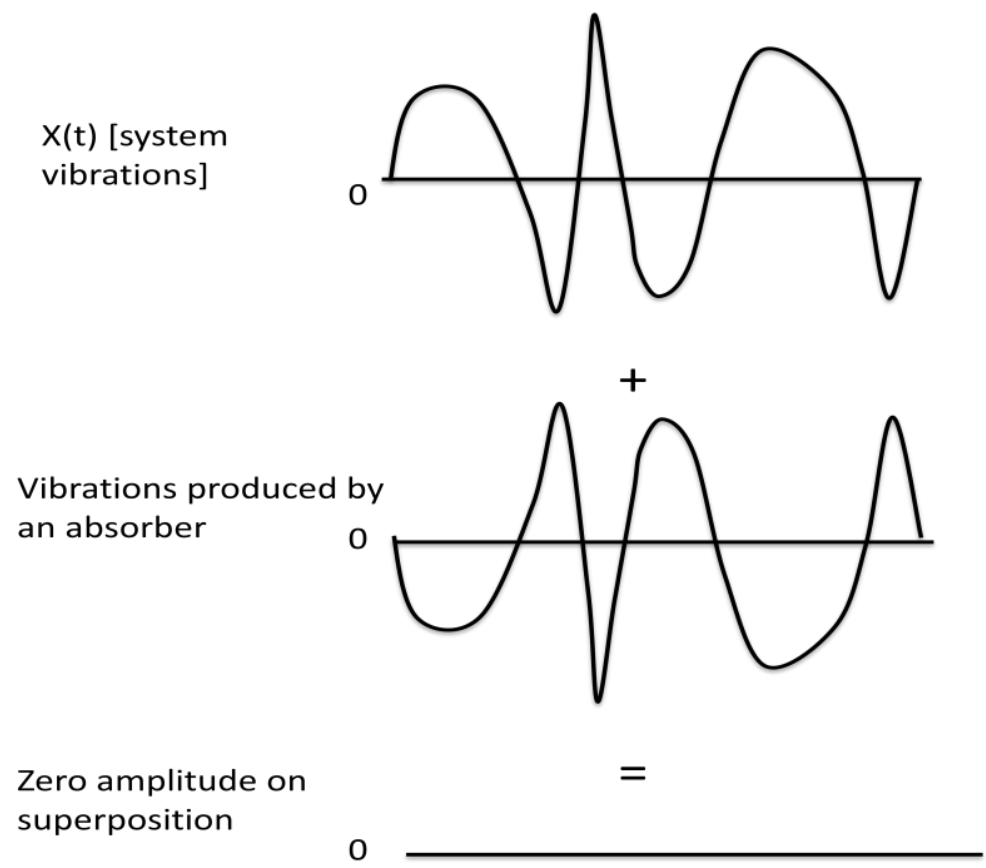

1.1. Vibration elimination 
An ideal absorber: Absorbers all vibrations, consumes minimum power, has minimum material and cost.

\subsection{Types of vibration absorbers}

Basically there are categories based on nature of frequency and dynamic characteristic of vibration absorbers.

On the basis of Nature of frequency the vibration absorber may be Dynamic vibration absorber or static vibration absorber (Tuned vibration absorber).

The basic difference between both of these are: In Dynamic vibration absorber the absorbing system senses the vibrations, gives actuating signal accordingly and absorbs vibration in a very high range of frequencies.

While for tuned vibration absorber: It is only tuned for a particular frequency and it cannot be used for wide range of frequencies.

In the classification based on the dynamic characteristic of vibration absorber may be of: 1) Active vibration absorber, 2) Passive vibration absorber.

\begin{tabular}{|l|l|}
\hline \multicolumn{1}{|c|}{ Active vibration absorber } & \multicolumn{1}{c|}{ Passive vibration absorber } \\
\hline $\begin{array}{l}\text {-In active vibration absorber the actuating } \\
\text { signal is given to the system that is all masses }\end{array}$ & $\begin{array}{l}\text { - In passive vibration type only the actuating } \\
\text { signals given is in the form of waves. }\end{array}$ \\
\hline $\begin{array}{l}\text {-In this absorber more power is consumed to } \\
\text { actuate }\end{array}$ & - Power consumed is less. \\
\hline $\begin{array}{l}\text {-Vibrations of the object may increase or } \\
\text { decrease }\end{array}$ & $\begin{array}{l}\text {-Vibration can only decrease in magnitude in } \\
\text { this case }\end{array}$ \\
\hline -It may produce negative or positive damping & -It only produces positive damping \\
\hline -Forced frequency is applied in this case & -Natural frequency is used in this case. \\
\hline
\end{tabular}

In passive type dynamic absorber system there is one more advantage that is we only get positive damping and not the negative damping in order to achieve only decrease in vibration magnitude.

So, our design is based on: Adaptive passive dynamic tuned vibration absorber.

\section{CONCEPTUALISATION}

\subsection{Our concept of design}

The design approach for the adaptive passive tuned dynamic vibration absorber is to make it of the design of double cantilever type. We designed it based on strength and further the length of the cantilever beams are designed based on the natural frequency to be obtained.

The double cantilever structure is attached to several other components to make it sense the vibration and actuate thereafter.

As shown in the figure, there is a column that supports two cantilever beams containing two point masses each of 1200 gram. 


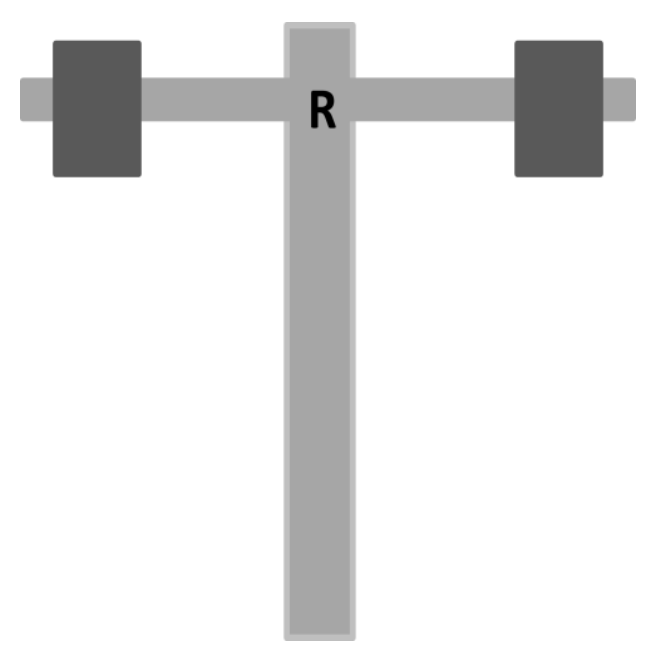

The point masses suspended creates a bending and due to that there is also a stiffness of this structure. Due to this stiffness there is a natural frequency of the structure itself and thus we can calculate various lengths in order to damp a vibrating system.

There are two point masses at the two extreme points of the rods. Two rods are being used one is threaded and another one is normal rod to constraint the rotational motion of the point mass when the threaded rod is given actuation using motors.

For complete vibration absorption we must assure that the vibration absorber system is vibrating on its $1^{\text {st }}$ mode. There may be several modes in which the system may be vibrating. These are as follows:

\section{$1^{\text {st }}$ mode}
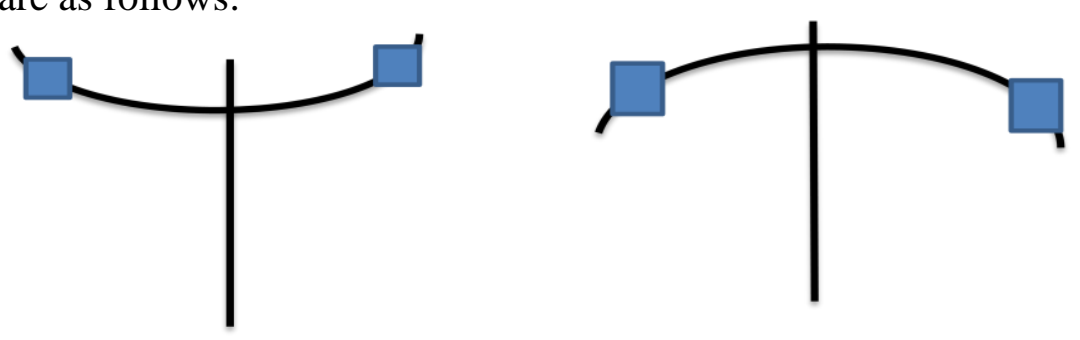

\section{$2^{\text {nd }}$ mode}
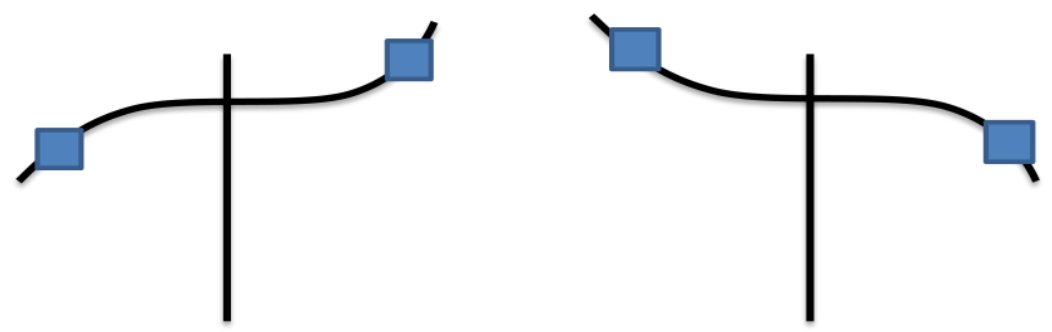

\subsection{Modes of the structure}

\subsection{Overall design}

The overall design consists of the various elements like sensor: In our case we have used the accelerometer ADXL335 sensor, the actuator which is our double cantilever structure, the processor which in our case is the Arduino Uno R3 which can be programmed to get a certain output and there is a stepper motor which is used for the actuation purpose connected with Arduino and the mechanical setup. The input of arduino is from the sensor accelerometer ADXL335. 


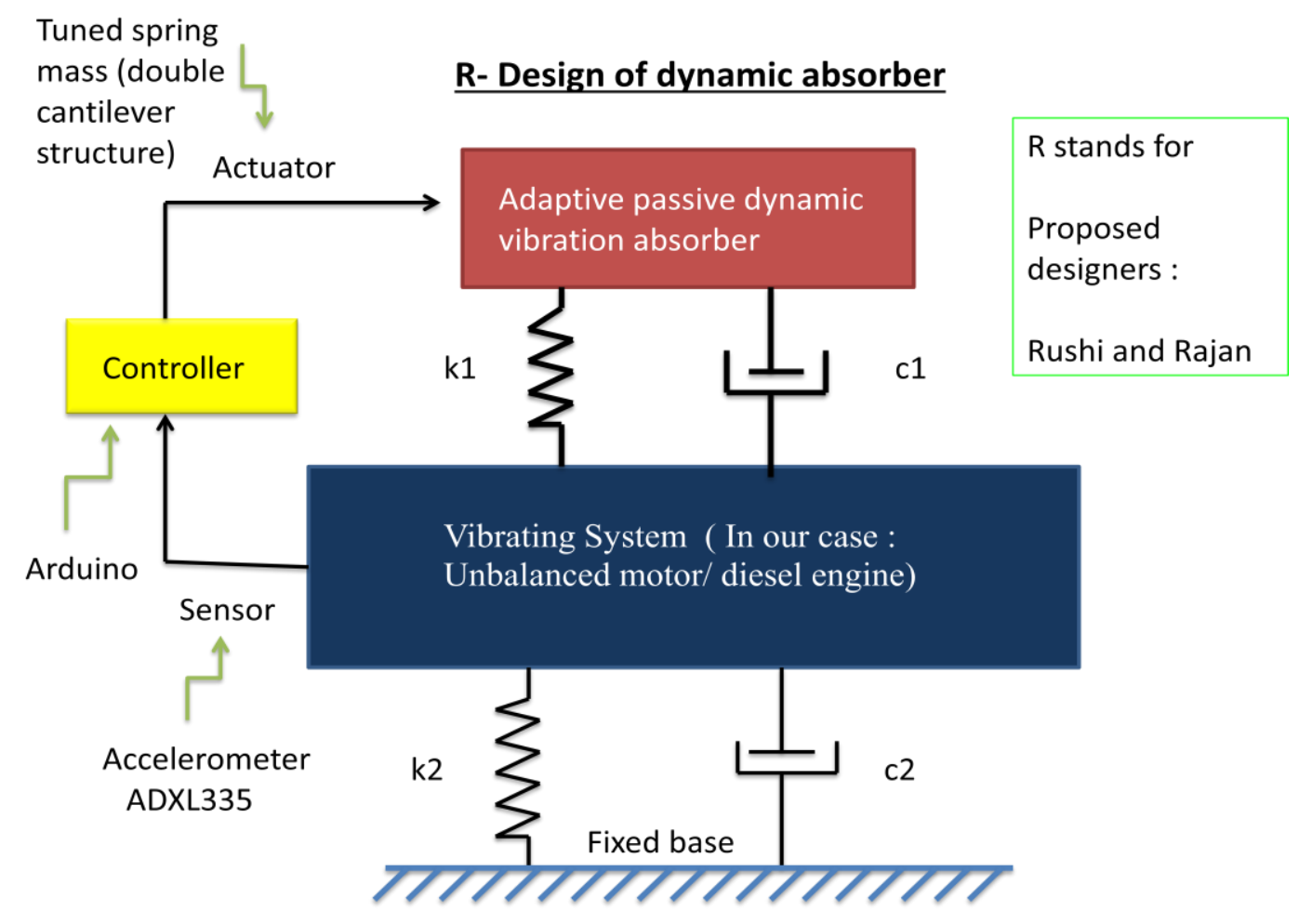

2.2. Design of vibration absorber

\subsection{FFT analysis readings}

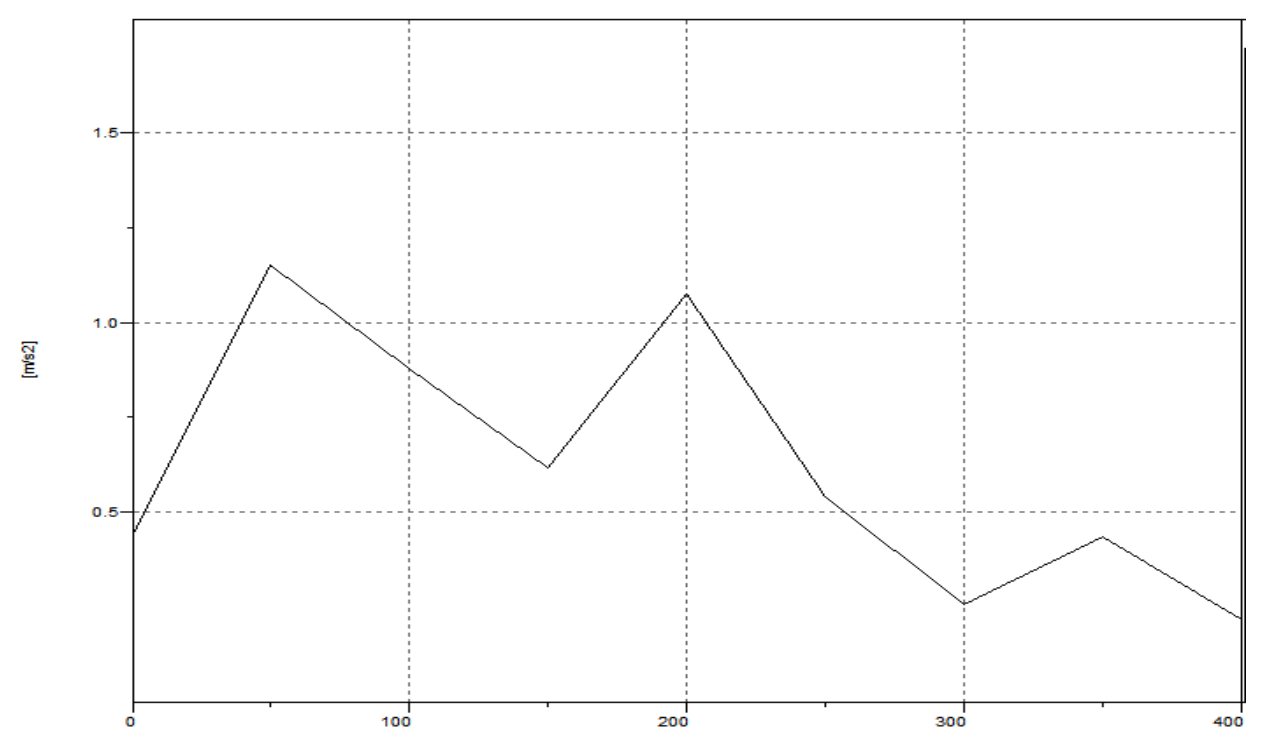

\subsection{FFT readings}

The curve above shows the curve of acceleration v/s frequency which gives magnitude of maximum acceleration at a particular frequency which means maximum force at a particular frequency which is at $50 \mathrm{~Hz}$ so that frequency to be damped at is at $50 \mathrm{~Hz}$ and corresponding acceleration is to be damped.

So the natural frequency of the adaptive tuned dynamic vibration absorber must be equal to the frequency of structure equal to $50 \mathrm{~Hz}$ to eliminate the vibrations. 


\section{DESIGN BASED ON STRENGTH}

The setup which is explained above has some mechanical parts and some electronic part. For the mechanical part we have to provide a sturdy design so as to assure the safe application of the whole setup in action.

So the various mechanical elements of the system are designed based on strength.

Basically, various iterations are carried out based on the values of diameter of rod and the point mass attached at the end of rod.

The factor of safety considered for the design is: 3.5

The point mass is decided based on iterations using software MS excel is 600 grams, and the diameter of rod is found out as $4.732 \mathrm{~mm}$ which is rounded off as $4.8 \mathrm{~mm}$.

The point masses apply the bending on the threaded rods as shown in the figure below.

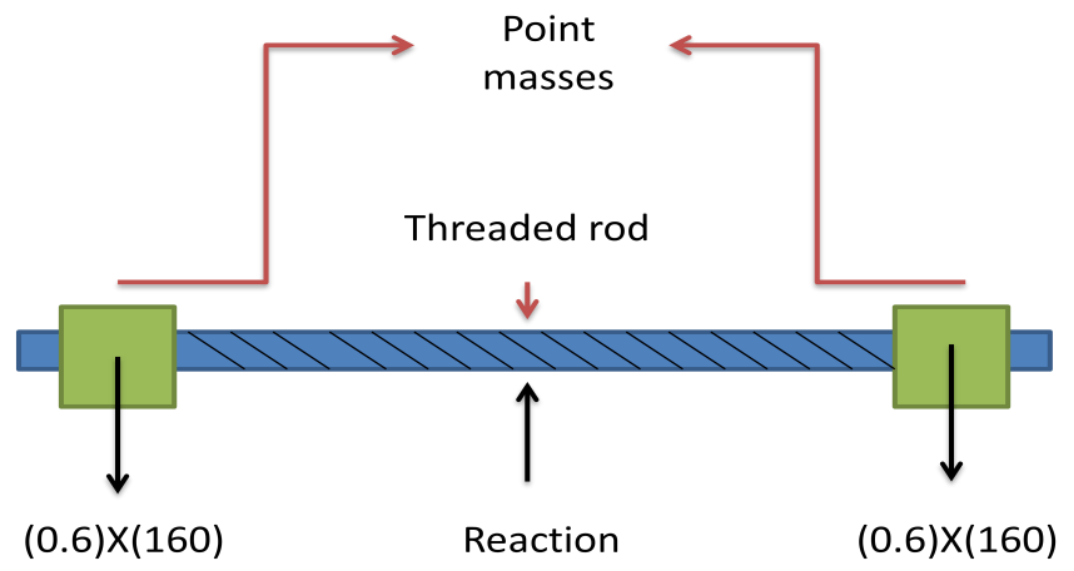

$(R)$

\subsection{Free body diagram of threaded rod}

So, the forces applied at the centre of the rod is as shown above so it has to be designed based on fatigue because when the setup will be kept on the working conditions there would be vibrations which may cause the mass to go from up and down so it is a case of pure fatigue loading. Pure reversed bending conditions.

The first and foremost approximation is the approximation regarding the point masses that we will be using in the apparatus. The weight of each point mass is 1.2 $\mathrm{kg}$. This acts at the extremity of the threaded rod.

First component to design is the rod. Rod is designed based on Fatigue criteria. Various derating factors $(\mathrm{Ka}, \mathrm{Kb}, \mathrm{Kc}, \mathrm{Kd}, \mathrm{Ke})$ are found out based on the various parameters and the endurance limit is found out from which the diameter of rod is found out and its length is found out using the frequency ranges.

$\mathrm{Ka}=$ surface finish factor, $\mathrm{Kb}=$ size factor, $\mathrm{Kc}=$ reliability factor (which is taken as $90 \%), \mathrm{Kd}=$ Load factor.

Factor of safety taken is 3.5.

Threaded rods are having less strength than normal rods, so for threaded rod the internal diameter is taken as the diameter obtained based on strength.

We have assumed the range of frequency as $30 \mathrm{~Hz}$ to $80 \mathrm{~Hz}$ and based on that the lengths are also found out using Dunkerley's rule as shown below: 


\subsection{Analysis part}

For the analysis purpose we can follow several approaches. The approach may be of discrete type or continuous type. We are following the discrete type approach for ease of analysis and calculations.

The assumption we made here is that the threaded rod is fixed from between so each side behaves as a cantilever beam. Thus it is considered as the double cantilever beam for analysis point of view.

Dunkerley's rule is applied on it as follows:

The two masses at the end as considered as the point masses and the threaded rod is also considered as a cantilever beam.

$$
\frac{1}{\omega_{1}{ }^{2}}=\frac{1}{\omega_{11}{ }^{2}}+\frac{1}{\omega_{22}{ }^{2}}+\ldots . .+\frac{1}{\omega_{n n}{ }^{2}}=\sum_{i=1}^{n} \frac{1}{\omega_{i i}{ }^{2}}
$$

wb of a cantilevered beam of mass, $\mathrm{m} 1$

$$
\omega_{b}^{2}=12.7 \cdot \frac{E I}{m_{1} l^{3}}
$$

$$
\begin{aligned}
\text { As } \mathrm{k} & =\omega^{2} \mathrm{~m}, \\
k & =12.7 \frac{E I}{l^{3}}
\end{aligned}
$$

Total stiffness by two rods: $\mathrm{Kt}=\mathrm{K} 1+\mathrm{K} 2$

$$
\therefore \omega_{b}^{2}=25.4 \frac{E I}{\mathrm{ml}^{3}}
$$

Where,

$\mathrm{I}=$ Moment of inertia of rod

$\mathrm{E}=$ modulus of elasticity of rod

$\mathrm{L}=$ length of cantilever

$\mathrm{m}=$ mass due to rod element $=($ density $) \mathrm{X}$ (volume $)$

Due to point mass attached at the end in the cantilever the natural frequency is

$$
\omega_{a}^{2}=\frac{3 E I}{m l^{3}}
$$

Where,

$\mathrm{m}$ is the total mass $=600 \mathrm{~g}+600 \mathrm{~g}=1.2 \mathrm{~kg}$

$\mathrm{E}=$ modulus of Elasticity of rod

L=length at which masses are suspended from middle 
$\mathrm{I}=$ moment of inertia

From this by keeping a certain value like in our case:

Mass $(\mathrm{m})=0.6 \mathrm{~kg}, \mathrm{E}=200 \mathrm{GPa}, \mathrm{L}=150 \mathrm{~mm}$

Frequency obtained is $47.56 \mathrm{~Hz}$

\subsection{Reasons for consideration of various elements}

The reason we considered the accelerometer ADXL335 is that the maximum acceleration we obtained using FFT curve was $15 \mathrm{~m} / \mathrm{s}^{2}$ and from the data book of electronics available on internet we found out that the sensor ADXL335 can sense the acceleration of upto $+3 \mathrm{~g}$ to $-3 \mathrm{~g}$. So it is in our desired range of vibrations and vibrations cannot increase more than this.

The actuator we are using to actuate the point masses in our double cantilever structure is the stepper motor. The reason for using stepper motor is the cost consideration and the signals that can be input in it which are in steps so an exact amount of displacement of the masses can be achieved simply by knowing the least count of actuation of the stepper motor and the pitch of the threads of the threaded rod of double cantilever structure.

For programming purpose the controller that we have used is the arduino UNO R3 for its

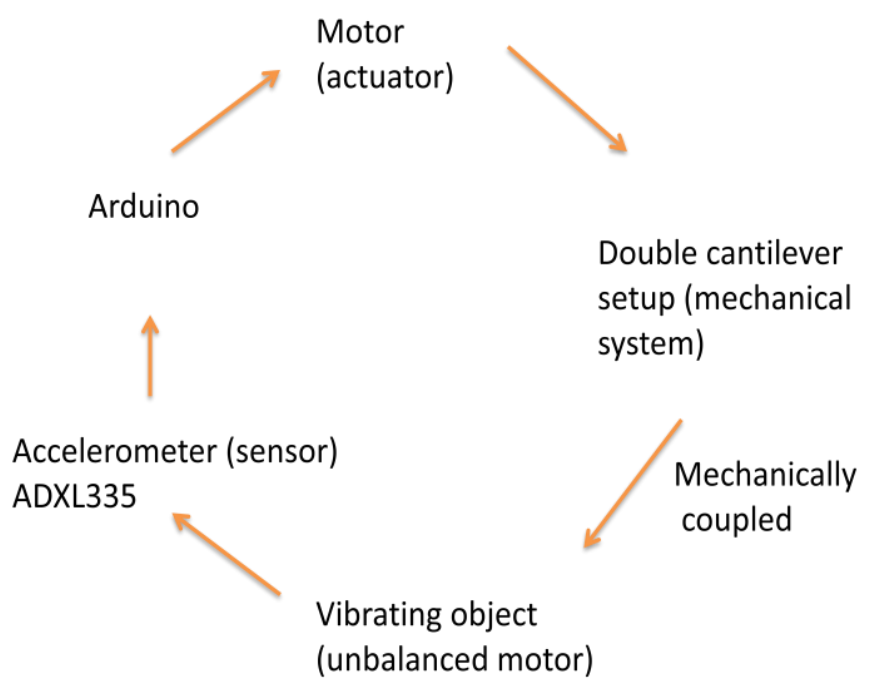

\subsection{Closed loop of the system}

Cost effectiveness and the serve of our purpose.

The mechanical and electric circuit must further become a closed loop system for constant monitoring and correction which can be done by considering this closed circuit.

\subsection{Solidworks modelling of the setup}

For the modelling in the CAD modelling software we have used the software Solidworks for the modelling and we have considered the setup to be completely made up of a column which supports two threaded rods and two point masses attached at the end of the threaded rods. As we know from the analysis part that the length we obtain for $50 \mathrm{~Hz}$ frequency is $110 \mathrm{~mm}$ so we have kept the masses at $110 \mathrm{~mm}$ to import it for analysis purpose. 


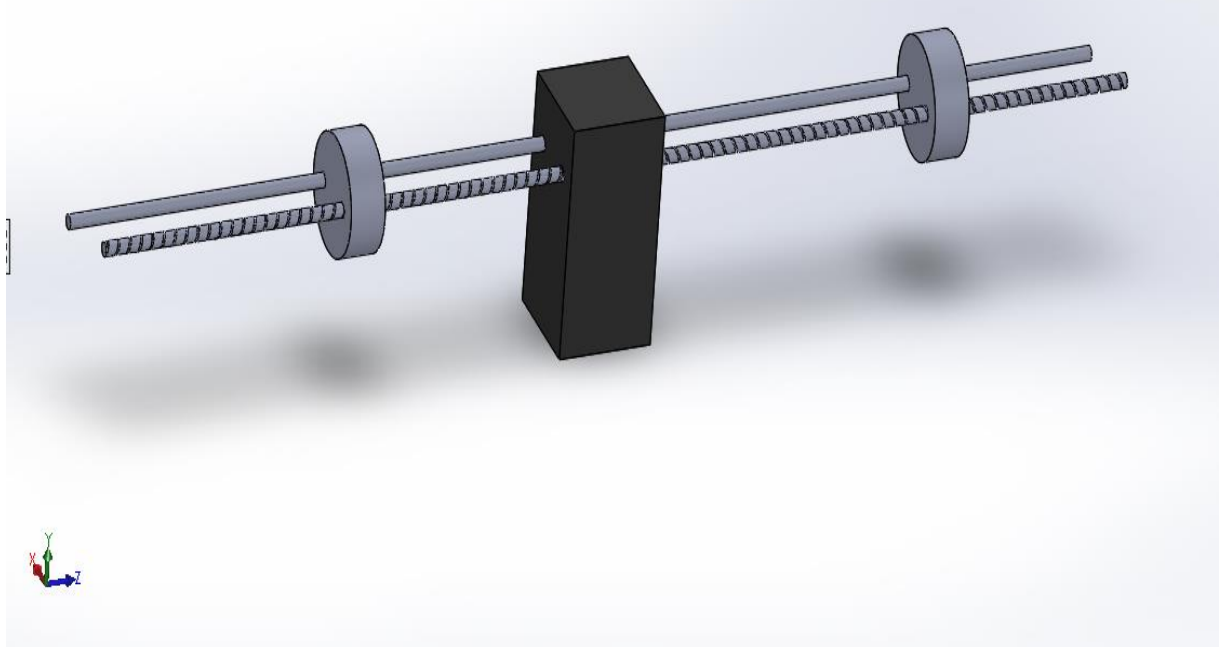

3.2. Solidworks 3-D modelling

\subsection{Ansys vibrational analysis results}

The model we made on solidworks is imported in Ansys software and the modal analysis of that particular system is done using the numerical FEA method. The figure below shows the meshed model of ansys

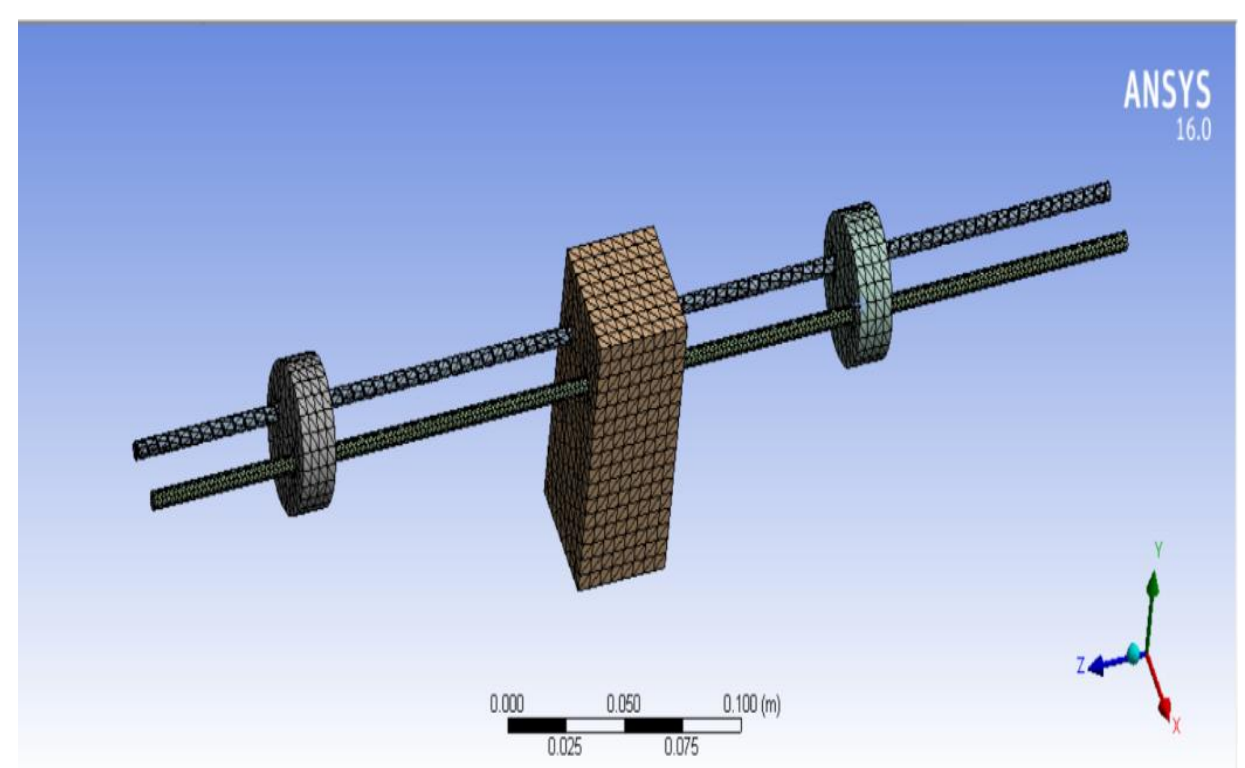

\subsection{Meshing of model elements}

The boundary conditions are given as:

The base of the structure is fixed.

The weight applied is only the masses on the rods.

Modal analysis is carried out and displacement and frequency probe are used

Mesh size: $5 \mathrm{~mm}$

Analysis: Finite element method 
Material:

For rods: Steel

Density: $7850 \mathrm{~kg} / \mathrm{m} 3$

$\mathrm{E}=200 \mathrm{Gpa}$

For column: Cast iron (no need of properties)

Boundary conditions:

Weight of masses and Fixed support at the bottom.

The results of ansys numerical analysis are as follows:

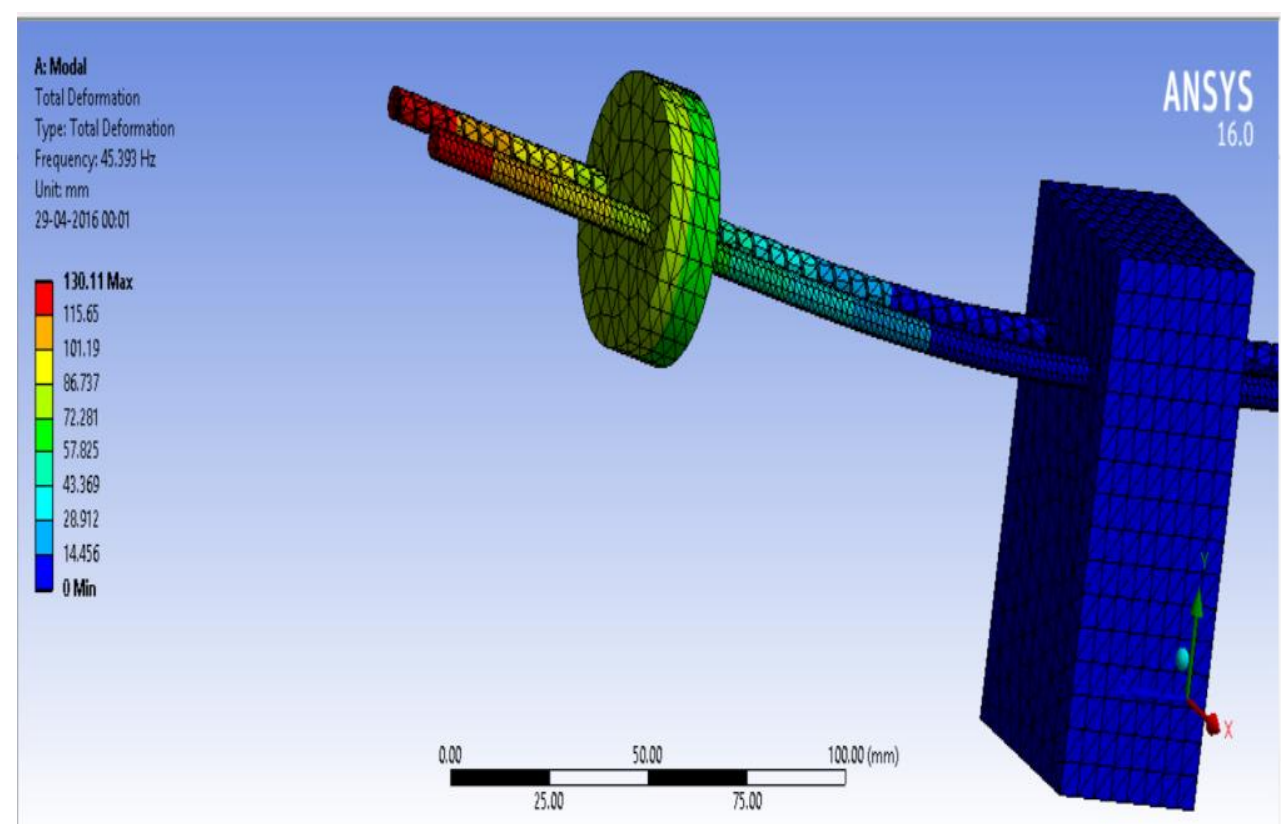

\subsection{Ansys solutions}

The natural frequency obtained in this analysis is $45.39 \mathrm{~Hz}$

\subsection{Comparison of analytical and numerical results}

As shown in the approach above the analytical results show nearly $47.56 \mathrm{~Hz}$ and numerical results show as $45.39 \mathrm{~Hz}$

\begin{tabular}{|c|c|c|}
\hline Analysis type & Natural frequency & \%error \\
\hline Analytical method & $47.56 \mathrm{~Hz}$ & $\begin{array}{c}4.54 \% \text { compared to } \\
\text { analytical }\end{array}$ \\
\hline Numerical method & $45.399 \mathrm{~Hz}$ & \\
\hline
\end{tabular}

The probable reasons for the difference may be: Meshed elements are not that high to get nearer to accurate results, still the error is very less so we can build this structure as it comes nearly equal in analytical and numerical analysis and it satisfactorily matches with the frequency of the base. 


\section{CONCLUSIONS}

Adaptive passive tuned dynamic vibration absorber is a very important type of vibration eliminator.

- It can replace several tuned vibration absorbers just by applying a single unit of it.

- Design of it is quite complex but it can be implemented to a very high range of varying frequency.

- Analysis based on analytical method and numerical method using ansys gives almost same results by error of just about $4 \%$

- $\quad$ Error in both the analysis may be due to the following reasons :

$>$ Numbers of mesh are very less.

> Some approximations in case of analytical methods for simplification

\section{REFERENCES}

[1] Design of an adaptive dynamic vibration absorber - Christopher Ting-Kong

[2] Ansys structural analysis guide

[3] University of Alberta tutorials : Modal analysis of a cantilever beam

[4] Cai C, Zheng H, Khan MS and Hung KC (2002) Modeling of material damping properties in ANSYS. In 2002 International ANSYS Conference Proceedings, Pittsburgh (PA), 22-24

[5] Peter Avitabile -Experimental Modal Analysis, A Simple NonMathematical Presentation on how to perform impact hammer test, University of Massachu-setts Lowell, Lowell, Massachusetts

[6] Agilent Technologies: The Fundamentals of Modal Testing, Applic. Rep. 243-2 (Agilent Technologies, Palo Alto 2000)

[7] Irshad M. Momin, Dr. Ranjit G. Todkar, "Design and Development of A Pendulum Type Dynamic Vibration Absorber For A SDOF Vibrating System Subjected To Base Excitation". International Journal of Mechanical Engineering and Technology (IJMET), 6(12), 2015, pp. 36-59.

[8] Nattadon Pannucharoenwong and Chawisorn Phukapak, "The Performance of Heat Absorber from Zinc on The Efficiency of Double Slope Solar Still". International Journal of Mechanical Engineering and Technology (IJMET), 6(12), 2015, pp. 36-59.

[9] A. Nagaraju and Prof. B. Uma Maheswar Gowd, "Nusselt Number and Friction Factor Correlations for Solar Air Heater Duct Having Triangular Protrusions as Roughness Elements on Absorber Plate". International Journal of Mechanical Engineering and Technology (IJMET), 6(4), 2015, pp. 35-44. 